TABLE

INFectious Diseases Designated as Notifiable at THE National LeVel-United States, 1994

AIDS

Anthrax

Aseptic meningitis

Botulism

Brucellosis

Chancroid

Cholera

Congenital rubella syndrome

Diphtheria

Encephalitis

Escherichia coli $0157: \mathrm{H} 7$

Gonorrhea

Granuloma inguinale

Haemophilus influenzae

Hepatitis A

Hepatitis B

Hepatitis, non-A, non-B

Hepatitis, unspecified

Legionellosis

Leprosy (Hansen disease)

Leptospirosis

Lyme disease

Lymphogranuloma venereum

Malaria

Measles

Meningococcal infection

Mumps

Pertussis

Plague

Poliomyelitis

Psittacosis

Rabies, animal

Rabies, human

Rheumatic fever

Rocky Mountain spotted fever (Typhus fever, tickborne)

Rubella

Salmonellosis

Shigellosis

Syphilis

Syphilis, congenital

Tetanus

Toxic shock syndrome

Trichinosis

Tuberculosis

Tularemia

Typhoid fever

Varicella (chickenpox) *

Yellow fever

* Although varicella is not officially a nationally notifiable disease. the Council of State and Territorial Epidemiologists encourage transmission of information about cases of varicella to the Centers for Disease Control and Prevention. Reprinted from M M WR 1994:43:801.

\section{Two New TB Training Videotapes Available}

Two new videotapes for training $\mathrm{HCWs}$ are available. Tracom has released three videotapes for use in healthcare facilities, institutional environments (eg, prisons, shelters, retirement homes) and for first responders. The videotapes review the epidemiology and modes of transmission of tuberculosis (TB), methods to recognize exposure situations, and strategies to reduce risks of exposure, including administrative and engineering controls and respiratory protection. For information, call Tracom at (800) 296-2660.

The American Journal of Nursing Company also released a videotape "TB or Not TB: New Guidelines for Prevention and Treatment." This videotape includes information on the epidemiology of TB, methods for assessing and screening patients, multidrug-resistant treatment regimens, and an overview of a respiratory protection program including the use of HEPA-filter respirators and fit testing. For information on purchase, rental, or preview, call (800) CALL-AJN.

\section{Survey: 1 in 4 Phlebotomists Stuck by Needle in 1 Year}

According to a survey conducted by the National Phlebotomists Association, about 1 in 4 phlebotomists have been stuck by a needle during the past year. The high rate of needlesticks among phlebotomists is related to hospitals supplying unsafe needles and providing little or no safety training, according the National Phlebotomists Association, an affiliation of the Service Employees International Union (SEIU).

According to the survey, $25 \%$ of the respondents received no training on preventing needlesticks and hazards of blood exposure on the job. There are currently no regulations that specifically prohibit the use of the needle and syringes without safety features. The SEIU has campaigned for several years for hospitals and manufacturers to phase out the needle bearing devices that do not have safety features. Jamie Cohem, SEIU's Assistant Director of Health and Safety, said that cost is the most cited barrier to the wider adoption of protective devices, but that the price can be expected to drop as the old needles are removed from the market and the new technology comes on line in large numbers.

\section{Prompt Rabies Diagnosis Eliminates Costly Postexposure Prophylaxis}

A high proportion of human rabies cases diagnosed in the United States have been acquired outside the country and have lacked a history of animal bite exposure. The CDC recently reported a case of rabies in a 40-year-old man who died in a hospital in Miami following a subacute and progressive neurologic syndrome; rabies had not been clinically suspected but was diagnosed postmortem. The man had frequently visited Haiti and is believed to have acquired his infection there.

Interviews with the family members indicated that 